\title{
Three Rare Concurrent Complications of Tertiary Hyperparathyroidism: Maxillary Brown Tumor, Uremic Leontiasis Ossea, and Hungry Bone Syndrome
}

\author{
Natalie Bransky, Neena Ramesh lyer, Sophie Mestman Cannon, Alexander Hanlin Tyan, Praneet Mylavarapu, \\ Ryan Orosco, David Brain Hom, Alan Ali Moazzam \\ Division of Hospital Medicine, UC San Diego Medical Center, San Diego, CA, USA
}

Corresponding author

Alan Ali Moazzam

Division of Hospital Medicine, UC San Diego

Medical Center, 200 West Arbor Drive, San

Diego, CA 92103, USA

Tel: +1-619-471-9193

Fax: +1-619-543-8255

E-mail: amoazzam@ucsd.edu

Received: April 16, 2020

Revised: June 26, 2020

Accepted: July 2, 2020
A 48-year-old woman in her 40's with end-stage renal disease and tertiary hyperparathyroidism (HPT) presented for a rapidly progressive maxillary tumor. Initial workup was notable for elevated intact parathyroid hormone (PTH) and diffuse thickening of skull and facial bones on computed tomography, and maxillary tumor biopsy with multinucleated giant cells. She underwent subtotal parathyroidectomy (with removal of a parathyroid adenoma and 2 hyperplastic glands) and partial resection of maxillary brown tumor. The patient's post-operative course was complicated by hungry bone syndrome, with hypocalcemia refractory to aggressive calcium repletion. Teriparatide (recombinant PTH) was utilized with rapid resolution of hypocalcemia. To our knowledge, this is the first case of maxillary brown tumor in tertiary HPT to be reported in the USA. This case also supports teriparatide as a novel therapeutic for hungry bone syndrome refractory to aggressive calcium repletion.

Key Words: Brown tumor $\cdot$ Hungry bone syndrome $\cdot$ Maxilla $\cdot$ Teriparatide $\cdot$ Tertiary hyperparathyroidism · Uremic leontiasis ossea

\section{CASE REPORT}

A woman in her 40's with history of lupus nephritis, end-stage renal disease (ESRD) of renal transplant on intermittent hemodialysis, type 2 diabetes mellitus, and tertiary hyperparathyroidism (HPT) presented to the emergency department for a rapidly progressive palate mass. The patient had a long-standing history of ESRD due to lupus nephritis and was dialysis-dependent for 10 years prior to renal transplant 18 years ago. Her ESRD had been complicated by renal osteodystrophy and severe osteopenia based on forearm radiographs, however, she did not complete dual energy $\mathrm{X}$-ray absorptiometry screening. Her renal transplant failed 3 years ago, necessitating re-initiation of hemodialysis. Her ESRD had been complicated by HPT, which progressed with failure of her transplant. Two months previously, the patient noted an oral palate mass and was referred to the Head and Neck Surgery clinic for biopsy. She was to return to the clinic for pathology results
Copyright $(\odot 2020$ The Korean Society for Bone and Mineral Research

This is an Open Access article distributed under the terms of the Creative Commons Attribution Non-Commercial License (https://creativecommons.org/licenses/by-nc/4.0/) which permits unrestricted non-commercial use, distribution, and reproduction in any medium, provided the origina work is properly cited.

\section{KSBMR}


and surgical planning, however, she presented to the Emergency Department for progressive difficulty eating, speaking, and mouth pain due to the oral mass.

On initial hospital evaluation, the patient was noted to have a firm, non-tender, exophytic mass approximately 5 $\mathrm{cm}$ in size on the right anterior aspect of the hard palate and malocclusion of related teeth. She had maxillofacial abnormalities including an expansion of the maxilla and

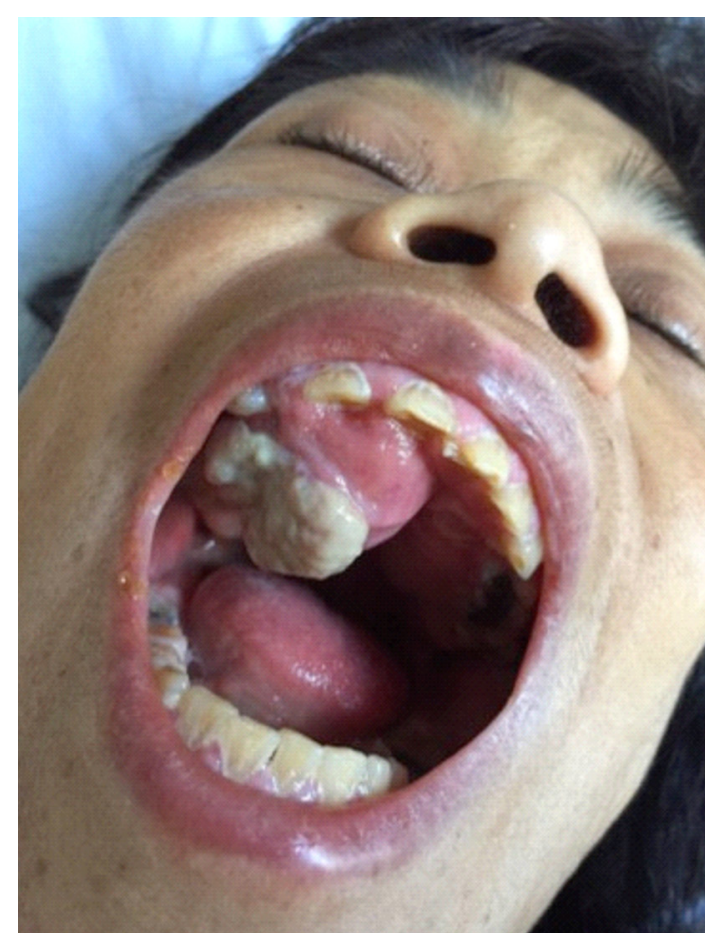

Fig. 1. Gross appearance of maxillary brown tumor. Color photograph of the maxillary tumor. The mass was sub-mucosal with visible ulceration of the mucosa due to trauma from the mandibular dentition. malocclusion of related teeth (Fig. 1). Laboratory studies on presentation were notable for normal corrected calcium, elevated phosphorus, elevated alkaline phosphatase and intact parathyroid hormone (PTH), and stable normocytic anemia (Table 1). Given the rapid progression and location of the mass, the patient was admitted for debulking of her maxillary tumor and parathyroidectomy. Computed tomography (CT) demonstrated extensive diffuse sclerosis and thickening of the calvarium, facial bones, and skull base (Fig. 2). Nuclear bone scan was also performed, showing diffuse increased uptake in the skull and mandible (Fig. 3). Pathology from the outpatient biopsy showed a fibrous background with scattered and clustered multinucleated giant cells, consistent with a diagnosis of maxillary brown tumor (Fig. 4).

\section{Treatment}

Head and Neck Surgery was consulted for sub-total parathyroidectomy and curettage of the maxillary tumor. Endocrinology and nephrology were also consulted for coordination of peri-operative care. The patient's pre-operative parathyroid hormone was over 4,400 , and normalized to 25 after subtotal parathyroidectomy. She was able to fully close her mouth after the palatal bone mass curettage with less mouth pain and improved oral intake. Surgical pathology demonstrated hypercellular parathyroid tissue, hard palate brown tumor, and 6 benign cervical lymph nodes.

After parathyroidectomy, the patient became symptomatically hypocalcemic with calcium as low as $6.2 \mathrm{mg} / \mathrm{dL}$, albumin $3.1 \mathrm{~g} / \mathrm{dL}$, ionized calcium $0.65 \mathrm{mMol} / \mathrm{L}$ (ref. 1.13-1.32 $\mathrm{mMol} / \mathrm{L}$ ), phosphorus $1.8 \mathrm{mg} / \mathrm{dL}$, and magnesium $2.1 \mathrm{mg} /$

Table 1. Pertinent laboratory results on presentation

\begin{tabular}{|c|c|c|c|c|}
\hline & Range & Admission & 1 month before admission & 2 months before admission \\
\hline Corrected calcium (mg/dL) & $8.5-10.6$ & 8.6 & 8.2 & 8.7 \\
\hline Phosphorus (mg/dL) & $2.7-4.5$ & 5.1 & 5.1 & 4.7 \\
\hline Magnesium (mg/dL) & $1.6-2.6$ & 2.1 & 2.3 & 2.1 \\
\hline Intact PTH (pg/mL) & $15-65$ & 3,089 & 4,477 & 3,073 \\
\hline Alkaline phosphatase (U/L) & $35-140$ & 1,098 & 1,349 & 1,396 \\
\hline 25(OH)D (ng/mL) & $30-80$ & 13 & - & - \\
\hline Creatinine (mg/dL) & $0.51-0.95$ & 2.92 & 3.73 & 4.31 \\
\hline Albumin $(\mathrm{g} / \mathrm{dL})$ & $3.5-5.2$ & 3.4 & 3.9 & 4.0 \\
\hline WBC $(K / \mu L)$ & $4.0-10.0$ & 7.3 & 6.6 & 7.6 \\
\hline Hemoglobin (g/dL) & $11.2-15.7$ & 11.2 & 11.7 & 11.3 \\
\hline Platelets $(\mathrm{K} / \mu \mathrm{L})$ & $140-370$ & 204 & 173 & 150 \\
\hline
\end{tabular}

PTH, parathyroid hormone; 25(OH)D, 25-hydroxy-vitamin D; WBC, white blood cell. 

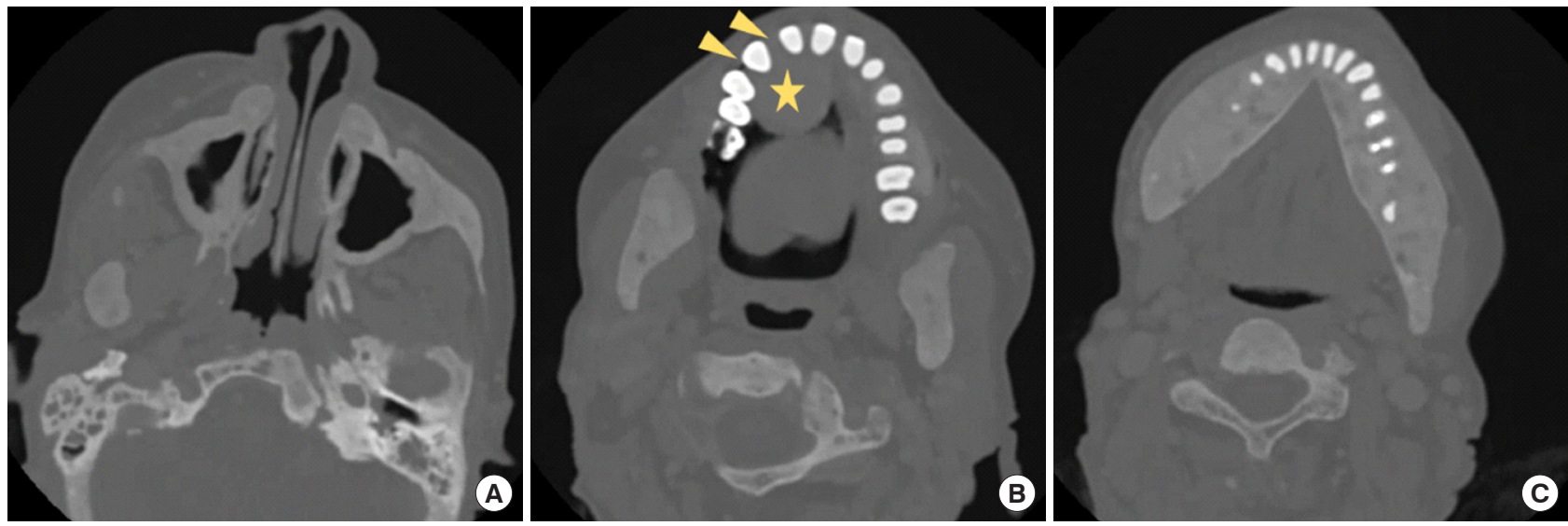

Fig. 2. Computed tomography (CT) appearance of oral tumor. Three panels of axial CT images, without contrast, demonstrating skull bone changes resulting from renal osteodystrophy. Thickening of the maxilla and zygoma (A), mandibular rami (B), and mandibular bodies (C). The maxillary tumor is visible in the center image as a round mass on the right anterior palate (star). The maxillary teeth are splayed (arrows).

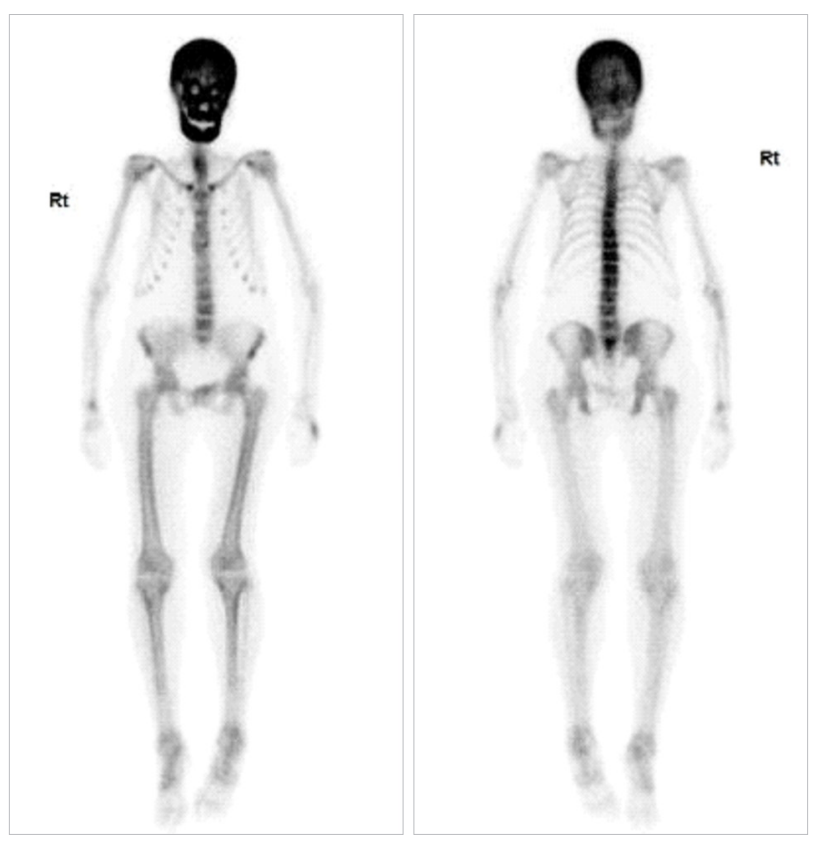

Fig. 3. Tc-99m MDP whole body bone scintigraphy. Nuclear bone scan images showing diffusely increased uptake in the skull, mandible, and spine consistent with renal osteodystrophy and uremic leontiasis ossea. Areas of mild focal uptake also seen in the manubrium and right 6 th rib corresponding to lytic lesion on computed tomography.

$\mathrm{dL}$, consistent with hungry bone syndrome. Despite the degree of hypocalcemia, her corrected QT interval did not prolong (410 ms compared to 445 pre-operatively). She was started on calcitriol, calcium carbonate, and IV calcium gluconate, and her hemodialysis sessions were increased to 3 times per week with a $3 \mathrm{mmol} / \mathrm{L}$ calcium dialysate. Despite doses as high as calcium carbonate 2,500 mg every 3 hr, calcitriol 2 mcg twice a day, and increased hemodialysis, the patient still required up to $12 \mathrm{~g}$ of IV calcium gluconate daily to keep her calcium in the 7 to $8 \mathrm{mg} / \mathrm{dL}$ range. Calcium citrate was attempted but led to a drop in calcium level despite dosing with equivalent elemental calcium. Our patient was started on teriparatide $20 \mathrm{mcg}$ twice daily on post-operative day 25 . Her ionized calcium in the days prior to initiation ranged between 0.79 and $0.83 \mathrm{mmol} / \mathrm{L}$. After several days of teriparatide, her ionized calcium normalized, and over time IV calcium requirement decreased. Phosphorus and magnesium were repleted as needed but were not as difficult to maintain within normal ranges.

She remained an inpatient for 1 month due to difficulty maintaining calcium levels. By time of discharge however, calcium became elevated to $11.0 \mathrm{mg} / \mathrm{dL}$, and teriparatide was stopped. She was later readmitted to the hospital for hypercalcemia of 13.8 likely due to a combination of resolving hungry bone syndrome and excessive pharmacologic supplementation. The patient did not have evidence of recurrent oral mass on post-surgical follow up and reported significant improvements in maxillofacial discomfort and oral intake.

\section{Methodology of Literature Review}

PubMed, Google Scholar, ScienceDirect, and Wiley databases were searched for all published cases of craniofacial brown tumors. A broad search strategy was employed using any combination of keywords from the following 2 groups: (1) group 1 - "craniofacial," "intraoral," "maxillofacial," "facial," "maxillary," "mandibular," and "orbital"; and (2) 

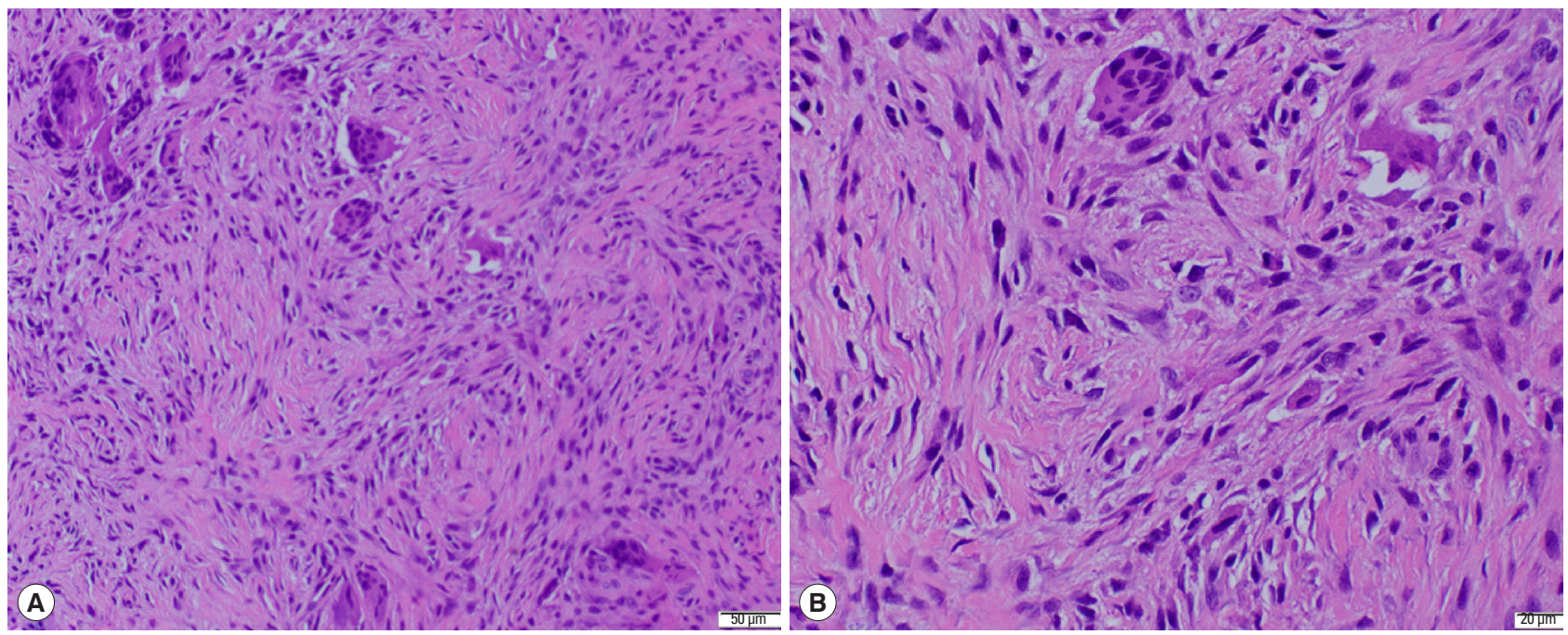

Fig. 4. Histopathology of tumor biopsy. Photomicrographs of tumor biopsy, showing scattered and clustered multinucleated giant cells in a fibrous background.

group 2 - "brown tumor" and "tumor of hyperparathyroidism." There were no constraints made on the date of publication. Search results were screened by title and abstract to select for case reports of craniofacial brown tumors. Many papers were drawn from references made in other relevant case reports found using our search strategy. Papers that met the following criteria were included in our data: (1) involvement of any brown tumor of the craniofacial region; (2) a well-described clinical course; and (3) a diagnosis of primary, secondary, or tertiary HPT. Author NPB performed the literature review.

\section{DISCUSSION}

We present a patient with 3 unique complications of tertiary HPT: maxillary brown tumor, uremic leontiasis ossea (ULO), and post-parathyroidectomy hungry bone syndrome. Tertiary HPT most commonly occurs in the setting of renal transplants. This condition results from prolonged hypocalcemia from vitamin D deficiency, leading to loss of feedback regulation to and autonomous function of parathyroid chief cells. Our patient's risk factors for developing this condition included failed renal transplant and ongoing hemodialysis. While tertiary HPT is classically caused by hyperplasia of all four glands, some reports indicate that over $20 \%$ may have single or double adenomas as the underlying pathology, as was the case for our patient who had one adenoma and 2 hypercellular glands on histopa- thology.[1]

\section{Uremic Leontiasis Ossea}

On presentation, our patient demonstrated thickened facial and skull bones, characteristic of ULO. ULO is a rare complication of secondary and tertiary HPT, resulting from mineralization defects and high bone turnover. On CT scan, ULO shows diffuse expansion of the maxillae and mandible with obliteration of the maxillary sinuses and protrusion of the mandible.[2-4] It is unclear why the cranial and facial bones are preferentially affected. As ULO progresses, the patient can experience dysphagia, speech impairment, vision loss due to compression of the optic nerve,[5] life-threatening airway obstruction, and exophthalmos. The only treatment to prevent further progression of ULO is parathyroidectomy, however, there is evidence that parathyroidectomy leads to improvement in the bone deformities. Fibrous dysplasia and Paget's disease of the bone can also resemble ULO but can be differentiated by history and biochemical evaluation.

\section{Craniofacial Brown Tumor}

Our patient presented with a rapidly progressive maxillary mass, which was diagnosed as a brown tumor. Brown tumors area rare complication of HPT manifesting as focal, bony lesions with increased osteoclastic activity and trabecular fibrosis.[6] This metabolic bone lesion derives its name from the abundant hemorrhage, hemosiderin depo- 
sition, and hypervascularity, which gives the tissue a dark red to brown color.[7] Although brown tumors may occur at any age, they occur more frequently in patients over 50 years of age. The prevalence is approximately 3 times greater in female patients.[8] Radiographically, brown tumors appear as radiolucent, uni- or multilocular lesions. They are often solitary but can also be multiple, and they can generate significant expansion of cortical bone in the long term. $[9,10]$ Histologically, brown tumors are characterized by highly vascular fibroblastic stroma with numerous multinucleated giant cells resembling osteoclasts.[7] This histopathology is not specific to brown tumors. Therefore, diagnosis is made using clinical, radiographic, histological, and laboratory data.

Brown tumors have become a rare entity in the developed world and are most commonly seen as an end-stage manifestation of primary HPT. The reported prevalence is $0.1 \%$.[11] They are reported to occur in $4.5 \%$ of patients with primary HPT and $1.5 \%$ to $1.7 \%$ of patients with secondary disease. $[8,11]$ Prevalence in patients with tertiary HPT is unknown and has rarely been reported.[10,12-16] Our systematic review of the medical literature yielded 95 cases (published from 1962 through 2020) of craniofacial brown tumors. Table 2 summarizes the results of the literature review.[6-82]

On review of the published cases of craniofacial brown tumors, we observed an equal distribution of tumors occurring in the maxilla and mandible (35.3\% and $37.6 \%$ ). There was a female predominance noted in both maxillary and mandibular tumors ( $70.0 \%$ and $75.8 \%$, respectively). Like our patient, many cases involved patients on hemodialysis (37.9\%), however, these patients primarily had secondary rather than tertiary HPT. To our knowledge, the present study represents the only case of maxillary brown tumor to be reported in a patient with tertiary HPT in the USA. We noted a paucity of data regarding the duration of HPT prior to development of brown tumors, with only 6 studies reporting this data (mean 108.6 months). The majority of cases were treated with either total or subtotal parathyroidectomy (48.6\%) alone, with tumor debulking or excision (24.3\%), or both (27.1\%). Remission was achieved in $91.2 \%, 100 \%$, and $94.7 \%$ of these cases, respectively.

First-line medical therapies for tertiary HPT focus on controlling hyperphosphatemia with dietary restriction, phosphate binders, vitamin D replacement, calcimimetic agents
Table 2. Literature review of published cases of craniofacial brown tumors

\begin{tabular}{|c|c|}
\hline & Value \\
\hline Age & $38.7 \pm 15.7$ \\
\hline \multicolumn{2}{|l|}{ Sex } \\
\hline Male & $24(28.2 \%)$ \\
\hline Female & $61(71.8 \%)$ \\
\hline \multicolumn{2}{|l|}{ Brown tumor location } \\
\hline Maxillary & $30(35.3 \%)$ \\
\hline Mandibular & $32(37.6 \%)$ \\
\hline Both & $23(27.1 \%)$ \\
\hline \multicolumn{2}{|l|}{ Hyperparathyroidism type } \\
\hline Primary & $39(45.9 \%)$ \\
\hline Secondary & $40(47.1 \%)$ \\
\hline Tertiary & $6(7.1 \%)$ \\
\hline \multicolumn{2}{|l|}{ Patient on HD } \\
\hline No & $41(62.1 \%)$ \\
\hline Yes & $25(37.9 \%)$ \\
\hline $\begin{array}{l}\text { Months on HD before brown tumor diag- } \\
\text { nosis }(n=25)\end{array}$ & $108.6 \pm 51.2$ \\
\hline \multicolumn{2}{|l|}{ Reported lab values } \\
\hline $\mathrm{iPTH}(\mathrm{n}=61)$ & $1,468.3 \pm 987.6$ \\
\hline $\mathrm{Ca}(n=56)$ & $11.2 \pm 2.8$ \\
\hline Phos (n=47) & $4.6 \pm 2.2$ \\
\hline $\operatorname{ALP}(n=40)$ & $1,122.7 \pm 1152.1$ \\
\hline \multicolumn{2}{|l|}{ Treatment } \\
\hline Parathyroidectomy & $34(48.6 \%)$ \\
\hline Remission & $31(91.2 \%)$ \\
\hline Local Excision & $17(24.3 \%)$ \\
\hline Remission & $17(100.0 \%)$ \\
\hline Both & $19(27.1 \%)$ \\
\hline Remission & $18(94.7 \%)$ \\
\hline
\end{tabular}

The data is presented as mean \pm standard deviation or number (\%). $\mathrm{HD}$, hemodialysis; $\mathrm{PTH}$, intact parathyroid hormone; Ca, calcium; Phos, phosphorus; ALP, alkaline phosphatase.

such as cinacalcet, and calcium supplementation.[83] National Kidney Foundation's Kidney Disease Quality Outcomes Initiative (KDOQI) recommends that patients with severe HPT (PTH > $800 \mathrm{pg} / \mathrm{mL}$ ) with hypercalcemia and/or hyperphosphatemia refractory to medical therapy be offered parathyroidectomy.[83,84] With maxillary bone brown tumor involvement, the bone lesion usually regresses after parathyroidectomy.[48] However, in some instances, the bone brown tumors can continue to grow after 2 years despite parathyroidectomy.[31] Thus, surgical excision of the brown tumor itself may be considered, especially if there are anatomic complications such as facial pain or compro- 
mised vision, hearing, chewing, speaking, and breathing. $[76,79]$ In this patient, her maxillary brown tumor significantly increased in size (doubling over 1 month), causing impaired oral intake and facial pain. Thus, surgical curettage of the maxillary bone lesion and parathyroidectomy were performed to palliate her pain and allow early-resumption of oral diet as her calcium homeostasis stabilized.

\section{Hungry Bone Syndrome}

While there are no standard pre-operative medical treatments for parathyroidectomy, pre-operative correction of low vitamin $\mathrm{D}$, and the use of bisphosphonates may assist in the prevention of complications such as hungry bone syndrome.[85] Hungry bone syndrome is defined as the rapid and prolonged hypocalcemia (longer than post-operative day 4) associated with both hypophosphatemia and hypomagnesemia that often follow parathyroidectomy.[85] The sudden decrease in PTH levels following removal of an adenoma and long-term suppression of the remaining glands lead to the arrest of bone resorption. In the face of continuing bone formation, this leads to increased skeletal use of calcium and subsequent hypocalcemia. Similar to the observed clinical course of our patient, hungry bone syndrome is usually associated with skeletal manifestations such as osteitis fibrosa cystica and brown tumors, as these indicate high pre-operative indices of bone turnover.[85] The prevalence of hungry bone syndrome after surgery is thought to be up to $13 \%$, though data is somewhat scarce.[85] Risk factors for the development of hungry bone syndrome include older age at the time of surgery, high levels of PTH and alkaline phosphatase, lower levels of albumin and magnesium, and skeletal abnormalities including subperiosteal erosions, lytic lesions, and brown tumors.[85] Interestingly, our patient had several of these risk factors including a significantly elevated PTH and alkaline phosphatase and skeletal abnormalities.

Treatment of hungry bone syndrome is aimed at replenishing the depleted skeletal calcium stores. The amount of calcium supplementation required to treat this severe hypocalcemia typically varies between 6 and $12 \mathrm{~g} /$ day.[85] After several weeks of around the clock IV (intravenous) and PO (oral) calcium supplementation, the patient had persistent and symptomatic hypocalcemia. While hypocalcemic, her magnesium was within normal range, and she received aggressive vitamin $\mathrm{D}$ supplementation.

\section{Teriparatide as a Novel Therapy for Hungry Bone Syndrome}

An extensive review of literature on hungry bone syndrome was completed to determine if any additional therapies could more effectively treat her hungry bone syndrome. The authors came across several case reports and case series highlighting the use of teriparatide therapy in this setting. Teriparatide is a recombinant human PTH (PTH 1-34) currently used for treatment of osteoporosis. Studies indicate that teriparatide may be a safe and effective treatment for hungry bone syndrome.[86] In a case series highlighting 5 case reports, teriparatide therapy was initiated between 2 weeks and 2 months after parathyroidectomy, resulting in the increase of serum calcium levels and reduction of calcitriol doses in some patients. In addition, phosphatemia levels and calcium carbonate requirements exhibited declining trends with therapy.[86] Our patient was started on teriparatide during her hospitalization and was able to be discharged 8 days after initiation as her calcium levels normalized. Teriparatide was discontinued upon discharge. Of note, she was re-admitted approximately 1 week later with hypercalcemia. She received hemodialysis and subsequently had protracted hypocalcemia during her second admission. This case highlights the difficulty of maintaining appropriate calcium homeostasis after parathyroidectomy in patients with ESRD, and the effective use of teriparatide for prolonged and refractory hypocalcemia due to hungry bone syndrome.

\section{CONCLUSIONS}

In summary, we present a case of tertiary HPT presenting with several unique features: parathyroid adenoma and hyperplasia of 2 glands, maxillary brown tumor, ULO. This case was collaboratively managed with head and neck surgery, endocrinology, nephrology, and primary teams. Her hospital course was complicated by hungry bone syndrome, a condition of refractory hypocalcemia that persisted for approximately one month after parathyroidectomy. We employed a novel therapeutic, teriparatide, for treatment of hungry bone syndrome with rapid resolution of hypocalcemia. 


\section{DECLARATIONS}

\section{Acknowledgments}

The authors would like to acknowledge Dr. Brian Datnow, Professor Emeritus of Pathology at UC San Diego, for providing histologic images for this case report. We also thank Dr. Scott Mullaney from the Department of Nephrology for his review and input on this case report.

\section{Ethics approval and consent to participate Not applicable.}

\section{Conflict of interest}

No potential conflict of interest relevant to this article was reported.

\section{ORCID}

Neena R lyer https://orcid.org/0000-0002-5557-7988

Sophie M Cannon https://orcid.org/0000-0003-1643-6944

Alexander L Tyan https://orcid.org/0000-0002-8221-9270

Praneet Mylavarapu https://orcid.org/0000-0003-0422-6982

Alan A Moazzam https://orcid.org/0000-0002-1867-0411

\section{REFERENCES}

1. Pitt SC, Sippel RS, Chen H. Secondary and tertiary hyperparathyroidism, state of the art surgical management. Surg Clin North Am 2009;89:1227-39.

2. Abdel Razek AA. Computed tomography and magnetic resonance imaging of maxillofacial lesions in renal osteodystrophy. J Craniofac Surg 2014;25:1354-7.

3. Han YH, Jeong HJ, Lim ST, et al. Uremic leontiasis ossea in a patient with chronic renal insufficiency demonstrated on bone scintigraphy. Clin Nucl Med 2016;41:641-2.

4. Lee VS, Webb MS, Jr., Martinez $S$, et al. Uremic leontiasis ossea: "bighead" disease in humans? Radiologic, clinical, and pathologic features. Radiology 1996;199:233-40.

5. Sundaram ANE, Abhayambika A, Kumar S. Bilateral compressive optic neuropathy from renal osteodystrophy caused by Branchio-oto-renal syndrome stabilised after parathyroidectomy. Neuroophthalmology 2017;41:321-5.

6. Verma P, Verma KG, Verma D, et al. Craniofacial brown tumor as a result of secondary hyperparathyroidism in chronic renal disease patient: a rare entity. J Oral Maxillofac Pathol 2014;18:267-70.
7. Soundarya N, Sharada P, Prakash N, et al. Bilateral maxillary brown tumors in a patient with primary hyperparathyroidism: Report of a rare entity and review of literature. J Oral Maxillofac Pathol 2011;15:56-9.

8. Keyser JS, Postma GN. Brown tumor of the mandible. Am J Otolaryngol 1996;17:407-10.

9. Queiroz SM, Vasconcelos RG, Leite de Andrade ALD, et al. Maxillary brown tumor associated with chronic kidney failure: a case report. J Bras Patol Med Lab 2013;49:424-8.

10. Noleto JW, Ramos IA, Rocha JF, et al. A rare case of regression of brown tumors of tertiary hyperparathyroidism after parathyroidectomy and renal transplant: A 5-year follow-up. Ann Maxillofac Surg 2016;6:125-9.

11. Proimos E, Chimona TS, Tamiolakis D, et al. Brown tumor of the maxillary sinus in a patient with primary hyperparathyroidism: a case report. J Med Case Rep 2009;3:7495.

12. Pinto LP, Cherubinim K, Salum FG, et al. Highly aggressive brown tumor in the jaw associated with tertiary hyperparathyroidism. Pediatr Dent 2006;28:543-6.

13. Selvi F, Cakarer S, Tanakol R, et al. Brown tumour of the maxilla and mandible: a rare complication of tertiary hyperparathyroidism. Dentomaxillofac Radiol 2009;38:53-8.

14. Magalhães DP, Osterne RL, Alves AP, et al. Multiple brown tumours of tertiary hyperparathyroidism in a renal transplant recipient: a case report. Med Oral Patol Oral Cir Bucal 2010;15:e10-3.

15. Dorigatti de Ávila É, de Molon RS, Cabrini Gabrielli MA, et al. Unusually rapid growth of brown tumour in the mandible after parathyroidectomy associated with the presence of a supernumerary parathyroid gland. J Craniomaxillofac Surg 2012;40:e19-23.

16. Dos Santos B, Koth VS, Figueiredo MA, et al. Brown tumor of the jaws as a manifestation of tertiary hyperparathyroidism: A literature review and case report. Spec Care Dentist 2018;38:163-71.

17. Rosenberg EH, Guralnick WC. Hyperparathyroidism: a review of 220 proved cases, with special emphasis on findings in the jaws. Oral Surg 1962;15:83.

18. Silverman S, Jr., Ware WH, Gillooly C, Jr. Dental aspects of hyperparathyroidism. Oral Surg Oral Med Oral Pathol 1968; 26:184-9.

19. Schweitzer VG, Thompson NW, McClatchey KD. Sphenoid sinus brown tumor, hypercalcemia, and blindness: an unusual presentation of primary hyperparathyroidism. Head Neck Surg 1986;8:379-86. 
20. Smith BR, Fowler CB, Svane TJ. Primary hyperparathyroidism presenting as a "peripheral" giant cell granuloma. J Oral Maxillofac Surg 1988;46:65-9.

21. Kanaan I, Ahmed M, Rifai A, et al. Sphenoid sinus brown tumor of secondary hyperparathyroidism: case report. Neurosurgery 1998;42:1374-7.

22. Scott SN, Graham SM, Sato Y, et al. Brown tumor of the palate in a patient with primary hyperparathyroidism. Ann Otol Rhinol Laryngol 1999;108:91-4.

23. Goshen O, Aviel-Ronen S, Dori S, et al. Brown tumour of hyperparathyroidism in the mandible associated with atypical parathyroid adenoma. J Laryngol Otol 2000;114:302-4.

24. Okada H, Davies JE, Yamamoto H. Brown tumor of the maxilla in a patient with secondary hyperparathyroidism: a case study involving immunohistochemistry and electron microscopy. J Oral Maxillofac Surg 2000;58:233-8.

25. Bereket $A$, Casur Y, Firat $P$, et al. Brown tumour as a complication of secondary hyperparathyroidism in severe longlasting vitamin D deficiency rickets. Eur J Pediatr 2000;159: 70-3.

26. Martínez-Gavidia EM, Bagán JV, Milián-Masanet MA, et al. Highly aggressive brown tumour of the maxilla as first manifestation of primary hyperparathyroidism. Int J Oral Maxillofac Surg 2000;29:447-9.

27. Guney E, Yigitbasi OG, Bayram F, et al. Brown tumor of the maxilla associated with primary hyperparathyroidism. Auris Nasus Larynx 2001;28:369-72.

28. Kar DK, Gupta SK, Agarwal A, et al. Brown tumor of the palate and mandible in association with primary hyperparathyroidism. J Oral Maxillofac Surg 2001;59:1352-4.

29. Merz MN, Massich DD, Marsh W, et al. Hyperparathyroidism presenting as brown tumor of the maxilla. Am J Otolaryngol 2002;23:173-6.

30. Al-Gahtany M, Cusimano M, Singer W, et al. Brown tumors of the skull base. Case report and review of the literature. J Neurosurg 2003;98:417-20.

31. Yamazaki H, Ota Y, Aoki T, et al. Brown tumor of the maxilla and mandible: progressive mandibular brown tumor after removal of parathyroid adenoma. J Oral Maxillofac Surg 2003;61:719-22.

32. Daniels JS. Primary hyperparathyroidism presenting as a palatal brown tumor. Oral Surg Oral Med Oral Pathol Oral Radiol Endod 2004;98:409-13.

33. Pinar Sumer A, Arik N, Sumer M, et al. A rare complication of secondary hyperparathyroidism. Brown tumor of the maxilla and mandible. Saudi Med J 2004;25:2010-2.

34. Yilmazlar S, Arslan E, Aksoy K, et al. Sellar-parasellar brown tumor: case report and review of literature. Skull Base 2004; 14:163-8; discussion 8.

35. Emin AH, Süoğlu Y, Demir D, et al. Normocalcemic hyperparathyroidism presented with mandibular brown tumor: report of a case. Auris Nasus Larynx 2004;31:299-304.

36. Throndson RR, Sexton SB. A mandibular central lesion with unusually rapid growth. Oral Surg Oral Med Oral Pathol Oral Radiol Endod 2004;98:4-9.

37. Lessa MM, Sakae FA, Tsuji RK, et al. Brown tumor of the facial bones: case report and literature review. Ear Nose Throat J 2005;84:432-4.

38. Fernández-Sanromán J, Antón-Badiola IM, Costas-López A. Brown tumor of the mandible as first manifestation of primary hyperparathyroidism: diagnosis and treatment. Med Oral Patol Oral Cir Bucal 2005;10:169-72.

39. Leal CT, Lacativa PG, Gomes EM, et al. Surgical approach and clinical outcome of a deforming brown tumor at the maxilla in a patient with secondary hyperparathyroidism due to chronic renal failure. Arq Bras Endocrinol Metabol 2006;50:963-7.

40. Zwick OM, Vagefi MR, Cockerham KP, et al. Brown tumor of secondary hyperparathyroidism involving the superior orbit and frontal calvarium. Ophthalmic Plast Reconstr Surg 2006;22:304-6.

41. Triantafillidou K, Zouloumis L, Karakinaris G, et al. Brown tumors of the jaws associated with primary or secondary hyperparathyroidism. A clinical study and review of the literature. Am J Otolaryngol 2006;27:281-6.

42. Guimarães ALS, Marques-Silva L, Gomes CC, et al. Peripheral brown tumour of hyperparathyroidism in the oral cavity. Oral Oncol Extra 2006;42:91-3.

43. Tarrass F, Benjelloun M, Bensaha T. Severe jaw enlargement associated with uremic hyperparathyroidism. Hemodial Int 2008;12:316-8.

44. Reséndiz-Colosia JA, Alvarado-Cabrero I, Flores-Díaz R, et al. Multiple maxillofacial brown tumors as primary hyperparathyroidism manifestation. Gac Med Mex 2008;144: 155-60.

45. Jebasingh F, Jacob JJ, Shah A, et al. Bilateral maxillary brown tumours as the first presentation of primary hyperparathyroidism. Oral Maxillofac Surg 2008;12:97-100.

46. Karabekmez FE, Duymaz A, Keskin M, et al. Huge deforming brown tumour at the maxilla and mandible in a pa- 
tient with secondary hyperparathyroidism. J Plast Reconstr Aesthet Surg 2008;61:1404-5.

47. Monteiro ML. Multiple brown tumors of the orbital walls: case report. Arq Bras Oftalmol 2009;72:116-8.

48. Sutbeyaz Y, Yoruk O, Bilen $\mathrm{H}$, et al. Primary hyperparathyroidism presenting as a palatal and mandibular brown tumor. J Craniofac Surg 2009;20:2101-4.

49. Di Daniele N, Condò S, Ferrannini M, et al. Brown tumour in a patient with secondary hyperparathyroidism resistant to medical therapy: case report on successful treatment after subtotal parathyroidectomy. Int J Endocrinol 2009; 2009:827652.

50. Fatma LB, Barbouch S, Fethi BH, et al. Brown tumors in patients with chronic renal failure and secondary hyperparathyroidism: report of 12 cases. Saudi J Kidney Dis Transpl 2010;21:772-7.

51. Pinto MC, Sass SM, Sampaio CP, et al. Brown tumor in a patient with hyperparathyroidism secondary to chronic renal failure. Braz J Otorhinolaryngol 2010;76:404.

52. Nabi Z, Algailani M, Abdelsalam M, et al. Regression of brown tumor of the maxilla in a patient with secondary hyperparathyroidism after a parathyroidectomy. Hemodial Int 2010;14:247-9.

53. Cecchetti DF, Paula SA, Cruz AA, et al. Orbital involvement in craniofacial brown tumors. Ophthalmic Plast Reconstr Surg 2010;26:106-11.

54. Alhusban M, Baqain ZH. Mandibular brown tumor as the first manifestation of primary hyperparathyroidism: A case report. Saudi Dent J 2011;23:107-9.

55. Jakubowski JM, Velez I, McClure SA. Brown tumor as a result of hyperparathyroidism in an end-stage renal disease patient. Case Rep Radiol 2011;2011:415476.

56. Bahrami E, Alireza T, Ebrahim H, et al. Maxillary and orbital brown tumor of primary hyperparathyroidism. Am J Case Rep 2012;13:183-6.

57. Praveen AH, Thriveni R. Maxillary and mandibular hyperparathyroidism. Natl J Maxillofac Surg 2012;3:51-4.

58. Sia HK, Hsieh MC, Yang LH, et al. Maxillary brown tumor as initial presentation of parathyroid adenoma: a case report. Kaohsiung J Med Sci 2012;28:400-3.

59. Pechalova PF, Poriazova EG. Brown tumor at the jaw in patients with secondary hyperparathyroidism due to chronic renal failure. Acta Medica (Hradec Kralove) 2013;56:83-6.

60. Guerrouani A, Rzin A, El Khatib K. Hyperparathyroidismjaw tumour syndrome detected by aggressive general- ized osteitis fibrosa cystica. Clin Cases Miner Bone Metab 2013;10:65-7.

61. Mori H, Okada Y, Arao T, et al. A case of multiple brown tumors with primary hyperparathyroidism. J Bone Miner Metab 2013;31:123-7.

62. Bindal R, Kumar A, Singh HP, et al. Evidence based solving approach in diagnosis of primary hyperparathyroidism with oral manifestations: report of three unusual cases. J Lab Physicians 2013;5:113-7.

63. Artul S, Bowirrat A, Yassin M, et al. Maxillary and frontal bone simultaneously involved in Brown tumor due to secondary hyperparathyroidism in a hemodialysis patient. Case Rep Oncol Med 2013;2013:909150.

64. Gadhia T, Adegun OK, Fortune F. Brown tumours: widespread involvement of multiple maxillofacial bones and cervical spine. BMJ Case Rep 2014;2014.

65. Loya-Solís A, Mendoza-García A, Ceceñas-Falcón L, et al. Sphenoid brown tumor associated with a parathyroid carcinoma. Case Rep Endocrinol 2014;2014:837204.

66. Aljalil A, Bouaity B. Brown tumor of the mandible revealing primary hyperparathyroidism: report of a case. Pan Afr Med J 2014;18:200.

67. Jafari-Pozve N, Ataie-Khorasgani M, Jafari-Pozve $S$, et al. Maxillofacial brown tumors in secondary hyperparathyroidism: A case report and literature review. J Res Med Sci 2014;19:1099-102.

68. Nunes TB, Bologna SB, Witzel AL, et al. A rare case of concomitant maxilla and mandible Brown tumours, papillary thyroid carcinoma, parathyroid adenoma, and osteitis fibrosa cystica. Case Rep Dent 2016;2016:5320298.

69. Shetty AD, Namitha J, James L. Brown tumor of mandible in association with primary hyperparathyroidism: a case report. J Int Oral Health 2015;7:50-2.

70. Kakade SP, Gogri AA, Umarji HR, et al. Oral manifestations of secondary hyperparathyroidism: a case report. Contemp Clin Dent 2015;6:552-8.

71. Huang R, Zhuang R, Liu Y, et al. Unusual presentation of primary hyperparathyroidism: report of three cases. BMC Med Imaging 2015;15:23.

72. Oliveira FM, Makimoto TE, Scalissi NM, et al. Regression of orbital brown tumor after surgical removal of parathyroid adenoma. Arch Endocrinol Metab 2015;59:455-9.

73. Qaisi M, Loeb M, Montague L, et al. Mandibular Brown tumor of secondary hyperparathyroidism requiring extensive resection: A forgotten entity in the developed world? 
Case Rep Med 2015;2015:567543.

74. Vahabzadeh-Hagh AM, Zipser BD, Tan HT, et al. More than just tissue diagnosis in a patient with maxillofacial bony lesions and hypercalcemia. Laryngoscope 2017;127:131821.

75. Queiroz IV, Queiroz SP, Medeiros R, Jr., et al. Brown tumor of secondary hyperparathyroidism: surgical approach and clinical outcome. Oral Maxillofac Surg 2016;20:435-9.

76. Can Ö, Boynueğri B, Gökçe AM, et al. Brown tumors: a case report and review of the literature. Case Rep Nephrol Dial 2016;6:46-52.

77. Brabyn P, Capote A, Belloti M, et al. Hyperparathyroidism diagnosed due to Brown tumors of the jaw: a case report and literature review. J Oral Maxillofac Surg 2017;75:2162-9.

78. Zou $H$, Song $L$, Jia $M$, et al. Brown tumor of multiple facial bones associated with primary hyperparathyroidism: a clinical case report. Medicine (Baltimore) 2018;97:e11877.

79. Kartini D, Siswiandari MK, Wibisana G, et al. Craniofacial Brown tumor in patients with secondary hyperparathyroidism to chronic renal failure: report of two cases in cipto mangunkusumo hospital. Case Rep Oncol Med 2018; 2018:1801652

80. Popovik-Monevska D, Bozovik-Dvojakovska S, Popovski V, et al. Brown tumour in the mandible and skull osteoscle- rosis associated with primary hyperparathyroidism - a case report. Open Access Maced J Med Sci 2018;6:406-9.

81. Chakravarti A, Shukla I, Mehra P, et al. Parathyroid adenoma in a young female presenting with craniofacial brown tumor and acute pancreatitis: a case report. Indian J Case Rep 2019;5:391-3.

82. Xu B, Yu J, Lu Y, et al. Primary hyperparathyroidism presenting as a brown tumor in the mandible: a case report. BMC Endocr Disord 2020;20:6.

83. Madorin C, Owen RP, Fraser WD, et al. The surgical management of renal hyperparathyroidism. Eur Arch Otorhinolaryngol 2012;269:1565-76.

84. National Kidney Foundation. K/DOQI clinical practice guidelines for bone metabolism and disease in chronic kidney disease. Am J Kidney Dis 2003;42:S1-201.

85. Witteveen JE, van Thiel S, Romijn JA, et al. Hungry bone syndrome: still a challenge in the post-operative management of primary hyperparathyroidism: a systematic review of the literature. Eur J Endocrinol 2013;168:R45-53.

86. Nogueira EL, Costa AC, Santana A, et al. Teriparatide efficacy in the treatment of severe hypocalcemia after kidney transplantation in parathyroidectomized patients: a series of five case reports. Transplantation 2011;92:316-20. 